Natural Hazards and Earth System Sciences (2004) 4: 583-598

SRef-ID: 1684-9981/nhess/2004-4-583

(C) European Geosciences Union 2004

Natural Hazards and Earth System Sciences

\title{
Parametric evaluation of 3D dispersion of rockfall trajectories
}

\author{
G. B. Crosta and F. Agliardi \\ Dipartimento di Scienze Geologiche e Geotecnologie, Università degli Studi di Milano-Bicocca, Italy \\ Received: 4 June 2004 - Revised: 1 October 2004 - Accepted: 4 October 2004 - Published: 11 October 2004 \\ Part of Special Issue "Monitoring and modeling of landslides and debris flows"
}

\begin{abstract}
The capability of evaluating and managing rockfall related risks is largely based on numerical modelling. Nevertheless, the reliability and accuracy of rockfall models is greatly affected by the strong uncertainty and spatial variability which characterise all the relevant parameters. In particular, 3D effects related to the variability of slope geometry and micro-topography play a major role in controlling the dynamics of falling blocks. The most important 3D effect is the "lateral dispersion" of rockfall trajectories, largely affecting the way we model rockfall dynamics, design countermeasures and assess rockfall hazard. Nevertheless, the dependence of lateral dispersion on different controlling factors has been hardly ever systematically evaluated.
\end{abstract}

In this paper, the influence of different controlling factors on the dispersion of rockfall trajectories has been systematically evaluated by performing 3D parametric modelling. Numerical simulations have been performed through a new software code able to use both a lumped mass and an hybrid (kinematic-dynamic) approach. Parametric modelling has been performed at different spatial resolutions using sets of biplanar simplified slopes characterised by different mean inclination and roughness. Model results outlined a complex dependence of lateral dispersion phenomena on slope mean gradient (macro-topography), slope roughness (micro-topography) and the spatial resolution of the model (model-dependent topography). Furthermore, the sensitivity of model results in terms of kinematic variables of motion (i.e. velocity and height to the ground) to the factors controlling lateral dispersion has been evaluated, resulting in practical constraints on countermeasure design and hazard assessment.

Correspondence to: G. B. Crosta

(giovannib.crosta@unimib.it)

\section{Introduction}

\subsection{Rockfalls}

Rockfalls are major hazards along natural and engineered slopes, and potentially threaten lives, settlements, facilities, lifelines and transportation corridors. Despite usually involving limited volumes (Varnes, 1978; Rochet, 1987; Hungr and Evans, 1988), rockfall phenomena are characterised by high energy and mobility. Thus, they are a major cause of landslide fatality, even when exposure of elements at risk is limited (e.g. along highways, Bunce et al., 1997). Rockfalls can be triggered by a variety of factors including earthquakes (Kobayashi et al., 1990), rainfall, freeze-and-thaw cycles (Matsuoka and Sakai, 1999) or the progressive chemical weathering of rock and discontinuities. According to the dynamic interactivity of single rock fragments, Rochet (1987) classified rockfalls into four categories, namely: single block falls (involved volume ranging between $10^{-2}$ and $10^{2} \mathrm{~m}^{3}$ ); mass falls $\left(10^{2}-10^{5} \mathrm{~m}^{3}\right)$; very large mass falls $\left(10^{5}-10^{7} \mathrm{~m}^{3}\right)$ and mass displacement (more than $10^{7} \mathrm{~m}^{3}$ ). The first two types (involved volume less than $10^{5} \mathrm{~m}^{3}$ ), also defined as "fragmental rock falls" (Hungr and Evans, 1988; Evans and Hungr, 1993), are characterised by null or negligible interaction among the falling blocks. Even when involving limited rock masses, fragmental rockfalls are extremely dangerous, because of their high spatial and temporal recurrence. Thus, rockfall hazard and risk assessment is required by safety and landplaning issues in developing mountain areas.

Rockfall modelling for practice requires assessing the envelope of trajectories, the maximum runout distance, the distribution of kinematic parameters along a fall path and the probability for a specified location to be reached by a specified "design block" (most probable or largest block). All this information results in the design of protective measures (Ritchie, 1963; Agliardi and Crosta, 2003) or in hazard assessment for land-planning and civil protection purposes (Crosta and Agliardi, 2003; Acosta et al., 2003). 
The description of evolution of fragmental rockfalls in space and time relies on the laws of mechanics (Wu, 1985; Bozzolo and Pamini, 1986; Bozzolo et al., 1988; Agliardi, 2003) and can be performed with different complexity by means of empirical relations (Evans and Hungr, 1993), kinematic (Stevens, 1998; Guzzetti et al., 2002; Agliardi and Crosta, 2003) or dynamic models (Bozzolo and Pamini, 1986; Bozzolo et al., 1988; Azzoni et al., 1995).

The reliability of mathematical rockfall models depends on their ability to account for the slope geometry and the energy loss at impact or by rolling. The task is difficult because of the dramatic uncertainty and spatial variability of the relevant parameters (size, shape and geomechanical properties of blocks, location of source areas, geometry and mechanical behaviour of surface material, etc.). Furthermore, energy loss is a complex function of a number of parameters (grain size distribution, void index and water content of surface material, block geometry and impact dynamics). Since the relationships controlling energy loss are not clearly stated, empirical "contact functions" (Pfeiffer and Bowen, 1989; Jones et al., 2000) are mostly used and expressed as restitution and friction coefficients, to be calibrated using different sources of information (literature datasets, experimental, geomorphological and historical data; Agliardi and Crosta, 2003).

\subsection{Lateral dispersion}

Reliable prediction of rockfalls is complicated by the threedimensional nature of actual slope geometry, affecting both the trajectories and the partition of kinetic energy into translational and rotational contributions. The trajectory of a block moving downslope can be deflected from the maximum slope by rolling within concavities and by impacting obliquely on the surface. This introduces a disorder effect in the pattern of fall paths, which becomes more relevant as the length of the fall path increases, since the error arising from the variability of the controlling parameters propagates over the increasing number of impacts and the morphological changes the block encounters.

At the slope scale, the most evident 3D effect is the occurrence of "lateral dispersion" (Broili, 1973; Bozzolo et al., 1988; Azzoni et al., 1995; Agliardi and Crosta, 2003), i.e. the ratio of the lateral distance separating the extreme fall paths to the slope length (Azzoni et al., 1995), giving a normalized representation of the maximum deviation of trajectories from the steepest gradient direction. According to Azzoni et al. (1995), lateral dispersion usually amounts to $20 \%$ of slope length, decreasing for short and steep slopes, but can be much larger for irregular or channeled slopes, as suggested by the geometry of debris cones (Evans and Hungr, 1993; Crosta and Locatelli, 1999). Also, high resolution numerical models performed by Agliardi and Crosta (2003) on natural rough and geometrically complex slopes, produced lateral dispersions as large as $34 \%$.

According to experimental and theoretical studies (Broili, 1973; Bozzolo et al., 1988; Azzoni et al., 1995), the factors controlling the onset of lateral dispersion phenomena can be classified in three groups, namely:

- macro-topographic factors, related to the overall slope morphology (maximum and average slope gradient, concavity and convexity, presence of chutes, channels, longitudinal and transversal ridges, see Fig. 1), directly affecting the trajectories of blocks, the motion type and the amount of translational and rotational kinetic energy;

- micro-topographic factors, related to the slope "roughness" (i.e. the local deviation from the average slope gradient), which is a function of the grain size distribution of slope debris, the strength of rock masses and the block size. Slope roughness affects both the energy loss by rolling or impact and the geometrical scattering of trajectories due to oblique rolls and bounces;

- dynamic factors, related to the interaction between slope features and block dynamics during bouncing and rolling. These factors include the inertial effects of block shape and size as well as the geometrical and dynamic configuration of impacts (impact angle and direction, translational and rotational velocity, torque generated at impact point, normal and tangential energy restitution, etc.).

In numerical simulations (Agliardi and Crosta, 2003), modelspecific controlling factors of lateral dispersion also arise, related to the nature and accuracy of the topographic model (e.g. vector, raster, etc.) or to the modelling algorithm (e.g. kinematic, hybrid or dynamic).

Lateral dispersion of rockfall trajectories can be represented through a "shadow cone" with the apex placed at the rockfall source area (Evans and Hungr, 1993; Cancelli and Crosta, 1993; Wieczorek et al., 1999; Crosta and Locatelli, 1999; Jaboyedoff and Labiouse, 2003). The "shadow cone" represents the extension in three dimensions of the "shadow angle" concept (i.e. the slope of the "energy line", according to Heim, 1932), allowing to include the influence of lateral dispersion in the evaluation of rockfall runout. Nevertheless, the angle of aperture of the shadow cone is usually evaluated on a largely subjective basis. Thus, a quantitative evaluation of lateral dispersion through experimental or numerical techniques is needed.

When performing numerical modelling of rockfalls for engineering purposes, lateral dispersion of trajectories often hampers the "a priori" choice of the rockfall path if a 2D modelling approach is adopted. Such a choice is largely subjective, possibly leading to unacceptable errors. From this perspective, lateral dispersion greatly affects our capability of designing effective countermeasures and assessing rockfall hazard at different scales. Thus, rockfall hazard zonation needs spatially distributed analyses (Acosta et al., 2003, Crosta and Agliardi, 2003) including a reliable modelling of lateral dispersion.

In this research, a modelling approach based on high resolution 3D numerical modelling (Agliardi and Crosta, 2002, 


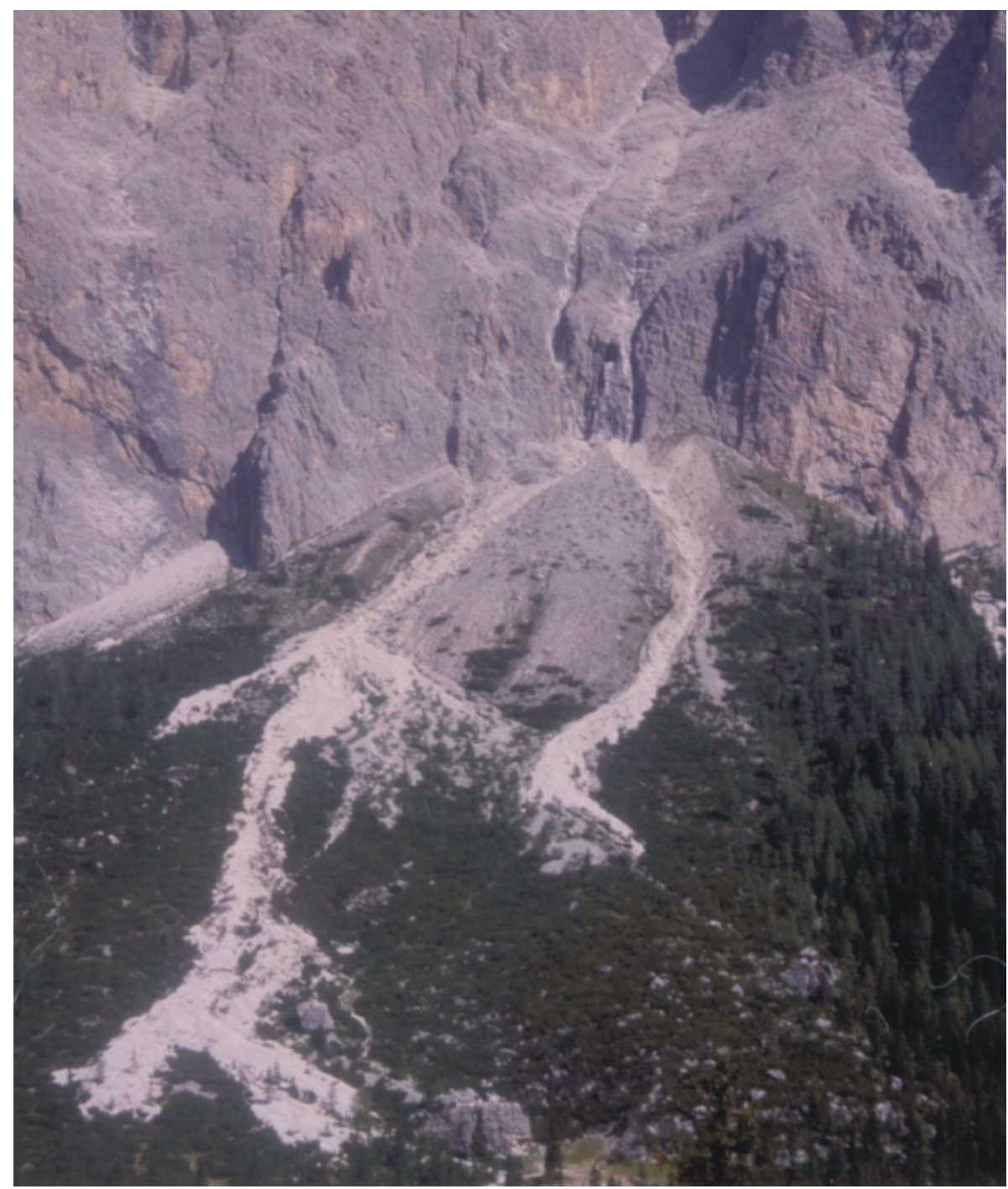

Fig. 1. Rocky cliff and talus cone near the Pordoi pass (Central-Eastern Alps, Italy). Picture shows the main topographic and morphological features controlling lateral dispersion of rockfall paths, e.g. chutes, channels, convex and rough talus cones etc. (photo courtesy T. Simonato).

2003; Crosta and Agliardi, 2003) has been employed to evaluate the dependence of lateral dispersion on different geometric and modelling parameters. Furthermore, this study faces the fundamental problem of evaluating the sensitivity of modelling results from local morphologies as well as from accuracy and resolution of the topographic description. In fact, the choice of the degree of accuracy in the topographic description of the study area is one of the major problems when planning and performing a site survey.

\section{Modelling approach}

The influence of macro-topographic, micro-topographic and model-specific factors on rockfall dynamics has been systematically evaluated by using an original rockfall 3D simulation program, developed starting from an old version of the software STONE (Guzzetti et al., 2002; Agliardi and Crosta,
2003), which is able to simulate a large number of 3D rockfall paths for fragmental rock falls (Hungr and Evans, 1988). At a first stage, a simple kinematic algorithm has been implemented in the code (Guzzetti et al., 2002), employing a high-resolution description of 3D slope geometry and introducing stochastic components. This kind of approach has been preferred to a more sophisticated dynamic one, in order to perform fast, accurate and easy-to-calibrate multiscale modelling. Moreover, we have presently developed a completely new release of the code (Crosta et al., 2004) implementing a hybrid (mixed kinematic-dynamic) modelling algorithm, with new capabilities added for probabilistic analyses, extended analysis tools and the possibility to introduce the effect of catch nets in the calculation.

The code has some specific features making it able to perform a large series of analyses both for landplanning and design purposes. It can use both a 3D kinematic and a hybrid algorithm allowing to model free fall, impact and 
Table 1. Summary of the simulation results in terms of lateral dispersion of the computed fall paths. The W/L ratio, chosen as the descriptor of lateral dispersion, has been evaluated according to the measuring scheme shown in Fig. 7 and reported as percent value.

\begin{tabular}{cccccc}
\hline & & \multicolumn{5}{c}{ Cell size $(\mathrm{m})$} \\
\hline & & 1 & 2 & 3 & 5 \\
\hline Roughness, $\sigma(\mathrm{m})$ & Average slope $\left(^{\circ}\right)$ & \multicolumn{5}{c}{ W/L $(\%)$} \\
\hline 0.1 & 25 & 7.8 & 5.2 & 3.4 & 2.7 \\
0.15 & 25 & 14.7 & 7.6 & 5.3 & 1.1 \\
0.2 & 25 & - & 11.0 & 7.8 & 2.8 \\
0.1 & 30 & 8.2 & 5.0 & 3.1 & 2.6 \\
0.15 & 30 & 15.3 & 7.8 & 4.2 & 1.2 \\
0.2 & 30 & 20.7 & 9.8 & 6.6 & 2.6 \\
0.1 & 37 & 8.3 & 3.3 & 2.1 & 1.9 \\
0.15 & 37 & 16.7 & 6.1 & 3.5 & 1.0 \\
0.2 & 37 & 26.4 & 7.9 & 5.7 & 2.3 \\
0.1 & 45 & 6.2 & 3.3 & 1.9 & 1.5 \\
0.15 & 45 & 17.4 & 4.5 & 3.0 & 0.7 \\
0.2 & 45 & 36.0 & 7.6 & 3.0 & 1.7 \\
0.1 & 52 & 5.3 & 3.4 & 1.7 & 1.1 \\
0.15 & 52 & 14.5 & 3.2 & 2.9 & 1.0 \\
0.2 & 52 & 25.7 & 7.5 & 2.6 & 1.0 \\
0.1 & 60 & 4.7 & 3.4 & 1.0 & 0.9 \\
0.15 & 60 & 11.9 & 4.3 & 2.2 & 1.0 \\
0.2 & 60 & 17.2 & 4.8 & 2.7 & 1.0 \\
\hline & & & &
\end{tabular}

rolling motions according to different approaches and including some semi-empirical damping relationships (Pfeiffer and Bowen, 1989; Jones et al., 2000), and specific rules to control the transition between rolling and bouncing modes (Guzzetti et al., 2002; Agliardi and Crosta, 2003).

Topography is introduced as a raster Digital Elevation Model (DEM), without resolution restrictions excepted for those regarding the hardware. Since 3D simulation of block paths requires a continuous description of topography, the code generates a vector (continuous) topographic model in the form of a Triangulate Regular Network (Guzzetti et al., 2002; Agliardi and Crosta, 2003), consisting of a net of triangles whose vertex coordinates are sampled from the DEM matrix (Fig. 2). In this framework, two reference coordinate systems are used during computations: a global "inertial" Cartesian system (XYZ) and a second Cartesian system local $\left(x_{p} y_{p} z_{p}\right)$ to each triangle.

Rockfall sources can be defined as points, polygons or lines, depending on the geomorphological pattern of rockfall sources and the type of available input data. In order to allow for probabilistic modelling, a different number of blocks can be thrown from each source cell, as a proxy of the different onset probability of rock falls from different sources.

All the input datasets (e.g. 3D topography, rockfall sources, normal and tangential restitution coefficients, $e_{n}$ and $e_{t}$, rolling friction coefficient, $\tan \phi_{r}$ ) are provided in a spatially distributed form, without limitations to the number of slope units used to describe surface lithology and land use.
The code allows to perform stochastic modelling, by varying all the relevant parameters within specified ranges according to different probability distributions. The analysis can be repeated through a "pseudo-random" approach.

Program outputs include 2D-raster and vector as well as 3D-vector outputs, including minimum, mean and maximum values of velocity, bounce height and kinetic energy at each computed point along fall paths, as well as information about the type of motion, the location of impacts and the maximum runout.

The results presented in this paper have been obtained by using the kinematic module of the new code, improved in trajectory computation and tracking.

\section{Parametric modelling}

\subsection{Model set-up}

Parametric numerical simulations have been performed to evaluate the sensitivity of modelling results to local morphology as well as to the accuracy of the adopted description of topography. We were particularly interested in separating the effects of macro- and micro-topography and understanding the sensitivity of the dispersion of rockfall trajectories and kinematic parameters to the spatial resolution of the topographic model.

In order to perform simulations, synthetic biplanar slopes have been numerically generated. Slopes are made up of two sectors: a sloping one with mean inclination $(\beta)$ values of $25^{\circ}, 30^{\circ}, 37^{\circ}, 45^{\circ}, 52^{\circ}$ and $60^{\circ}$ (Fig. 3 ), covering the range of the most common talus and rocky slopes, and a bottom flat sector with mean slope equal to $0^{\circ}$. Furthermore, three different roughness conditions (Table 1) have been introduced to simulate micro-topography (e.g. small steps, presence of large boulders or of a blocky and rough surface, etc.). Synthetic slope sets have been created by generating grids of random elevation data, sampled from a normal probability distribution with a fixed mean value of $0.25 \mathrm{~m}$ and different standard deviation values $(\sigma: 0.1 \mathrm{~m}, 0.15 \mathrm{~m}$ and $0.2 \mathrm{~m})$, simulating different roughness conditions. The rough sloping sector of the biplanar slopes has been obtained through geometrical transformation of parts of the generated grids.

Such a procedure allowed to generate different Digital Elevation Models in Esri ${ }^{T M}$ GridAscii format, with a cell size of $1 \mathrm{~m}$ and extent in the $\mathrm{x}$ and $\mathrm{y}$ direction of $500 \mathrm{~m}$ and 1000 m, respectively (Fig. 4).

Furthermore, digital terrain models with resolutions (pixel size) of $2 \mathrm{~m}, 3 \mathrm{~m}$ and $5 \mathrm{~m}$ have been generated by resampling the original $1 \mathrm{~m}$-resolution datasets, in order to analyse the effects of resolution up-scaling starting from the same basic topographic information. In engineering practice, this could be the result both of the particular technique adopted for slope topographic survey (ground based topographic survey, aero-photogrammetric survey, ground based laser scanning, aerial LIDAR, etc.) and the inherent logistic difficulties (small cliffs, vegetation, etc.). 

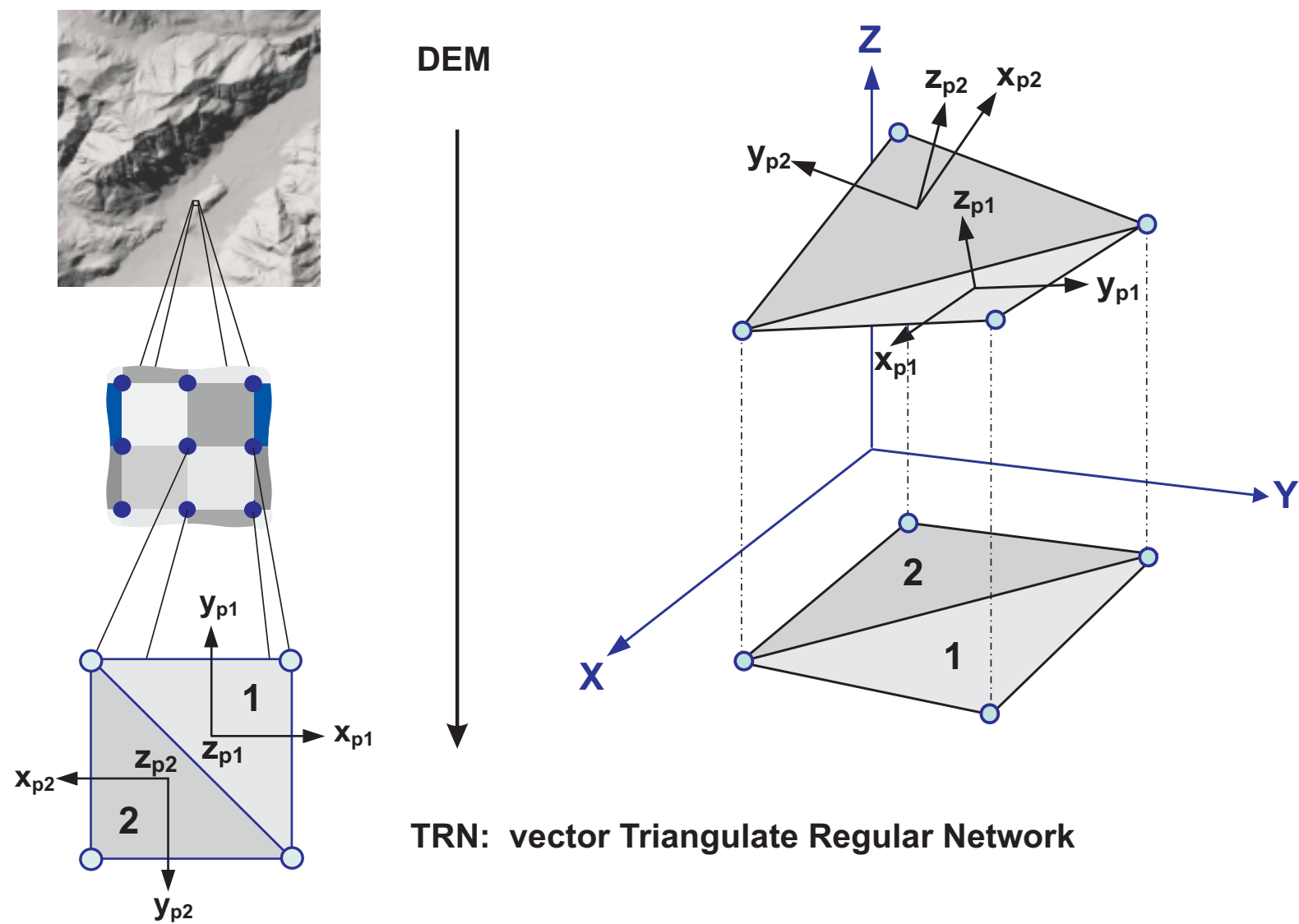

TRN: vector Triangulate Regular Network

Fig. 2. Sketched description of the TRN (Triangulate Regular Network) topographic model built by the computer code STONE starting from a raster square grid of elevation points.

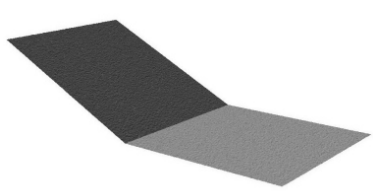

$\beta=25^{\circ}$

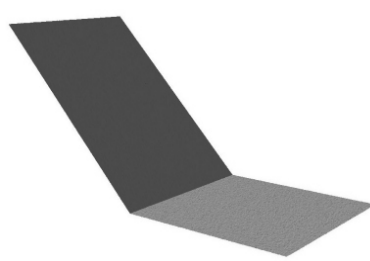

$$
\beta=45^{\circ}
$$

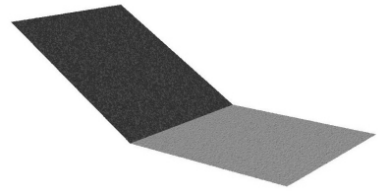

$\beta=30^{\circ}$

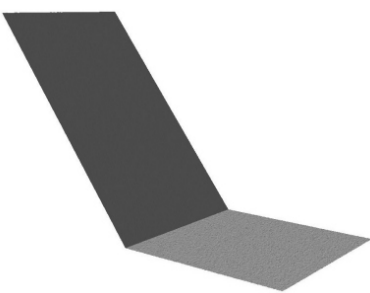

$\beta=52^{\circ}$

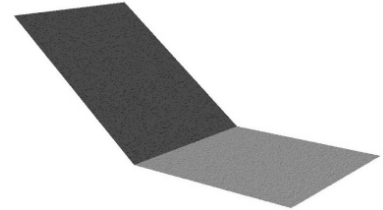

$\beta=37^{\circ}$

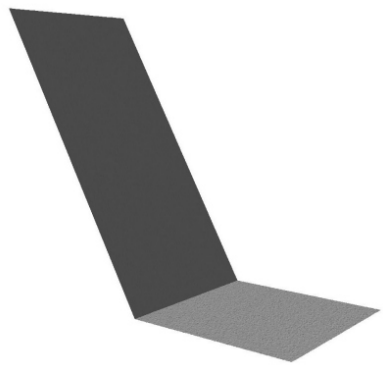

$\beta=60^{\circ}$

Fig. 3. 3D views of the synthetic biplanar slopes, generated by geometrical transformation of normally-distributed sets of random elevation data. Slopes with average inclination $(\beta)$ of $25^{\circ}, 30^{\circ}, 37^{\circ}, 45^{\circ}, 52^{\circ}$ and $60^{\circ}$ have been generated at different spatial resolution $(1,2,3$ and $5 \mathrm{~m})$ and with different standard deviation values $(\sigma=0.1,0.15$ and $0.2 \mathrm{~m})$ reproducing micro-topographic features. 

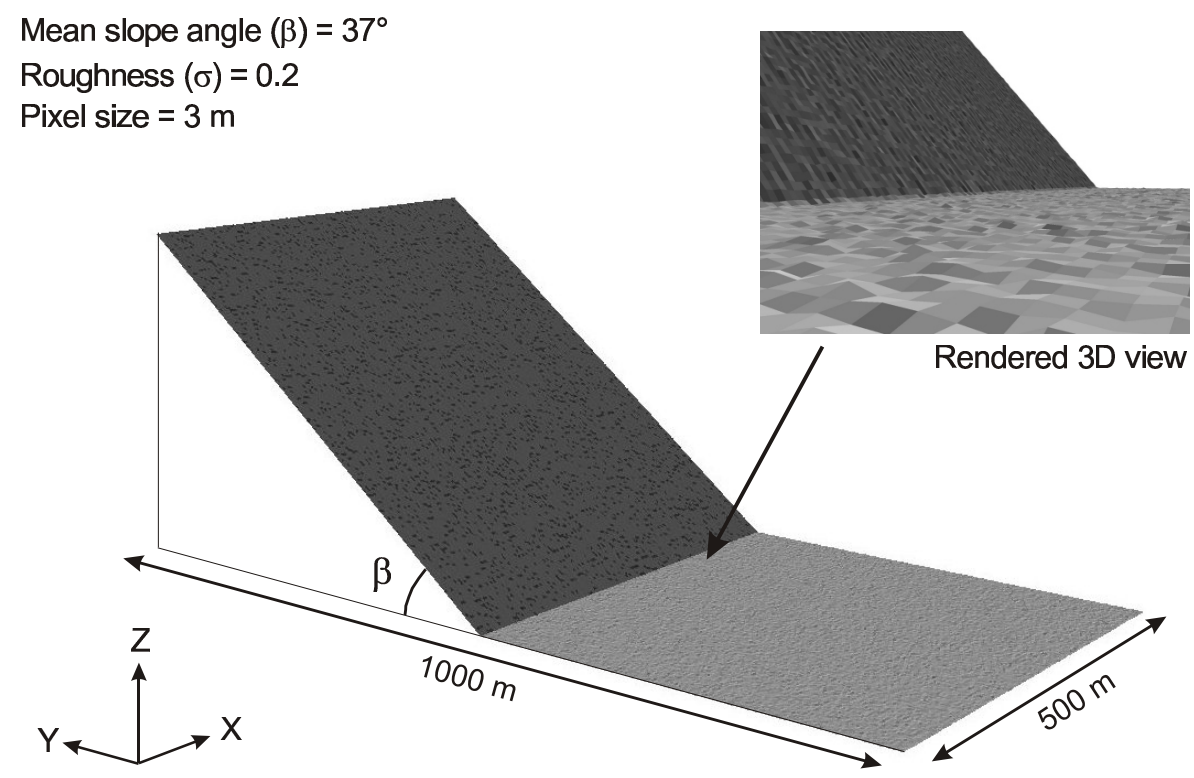

Fig. 4. Example showing the main geometrical features of the synthetic biplanar slopes used for parametric simulations: average slope $(\beta)$, surface roughness $(\sigma)$ and spatial resolution (pixel size). In the inset a rendered, 3D representation of slope roughness (micro-topography) is shown.

In order to analyse the specific effects of microtopographic variability (Fig. 4), simulations have been performed under constant simulation conditions. These conditions include:

- fixed values for the normal and tangential restitution and friction coefficients (specifically: $e_{n}: 0.35 ; e_{t}: 0.75$; $\tan \phi_{r}: 0.4$ ), without any velocity damping introduced;

- fixed range of variability of the relevant parameters (starting angle on horizontal plane: $\pm 1 \%$; restitution coefficients: $\pm 1 \%$; friction coefficient: $\pm 1 \%$ );

- fixed initial conditions (e.g. source area size and position, initial velocity);

- fixed simulation conditions (number of computed trajectories, minimum threshold velocity, bouncing-rolling transition threshold value)

The imposed stochastic variability of the parameters is very limited with respect to that normally adopted, in order to better outline the effects of slope morphology (mean inclination, $\beta$ ), micro-topography (roughness, $\sigma$ ) and resolution of the topographic model (DEM cell size).

Finally, a constant representative number of blocks (imposed equal to 1000) was launched from a cluster of cells forming a square source area of $100 \mathrm{~m}^{2}$, to provide homogeneous cover and statistical significance. Since decreasing grid resolution results in a lower number of source cells in a given area, the number of blocks thrown from every source cell has been varied depending on model resolution.

\subsection{Sensitivity analysis of lateral dispersion}

A total number of 72 simulations (Table 1 ) have been performed at resolutions of 1, 2, 3 and $5 \mathrm{~m}$, respectively (Fig. 5), with all the different combinations of mean slope inclination $(\beta)$ and slope roughness ( $\sigma$, see Fig. 6). Model results have been exported as vector files portraying, at each point along 3D trajectories, the computed values of velocity and height to the topography (Fig. 7).

The analysis of simulation results has been based on the evaluation of the $\mathrm{W} / \mathrm{L}$ ratio (i.e. the ratio of the width, $\mathrm{W}$, to the length, L, of the invasion area; see Fig. 7), which has been selected as the descriptor of the lateral dispersion occurring during the simulations.

Because of the adopted geometrical transformation procedure, the downslope length of the sloping sector is different for biplanar slopes with different mean inclination (Fig. 3). Nevertheless, the W/L ratio needs to be evaluated at a fixed travel distance from the source, in order to be compared over different simulations. Thus, the width of the invasion area, $\mathrm{W}$, has been sampled at a variable horizontal distance from the source (Fig. 7), depending on the mean slope inclination and corresponding to a fixed downslope travel distance (L) of $580 \mathrm{~m}$ (i.e. the travel distance to the slope toe for the $30^{\circ}$ slope).

Values of the W/L ratio obtained for each simulation are shown in Table 1 as percent values. In this research, we were more interested in evaluating the sensitivity of the W/L ratio to different controlling parameters than in obtaining absolute values of the descriptor. These can vary according to the adopted modelling algorithm (kinematic, hybrid, etc.) and to a variety of model-specific conditions. 

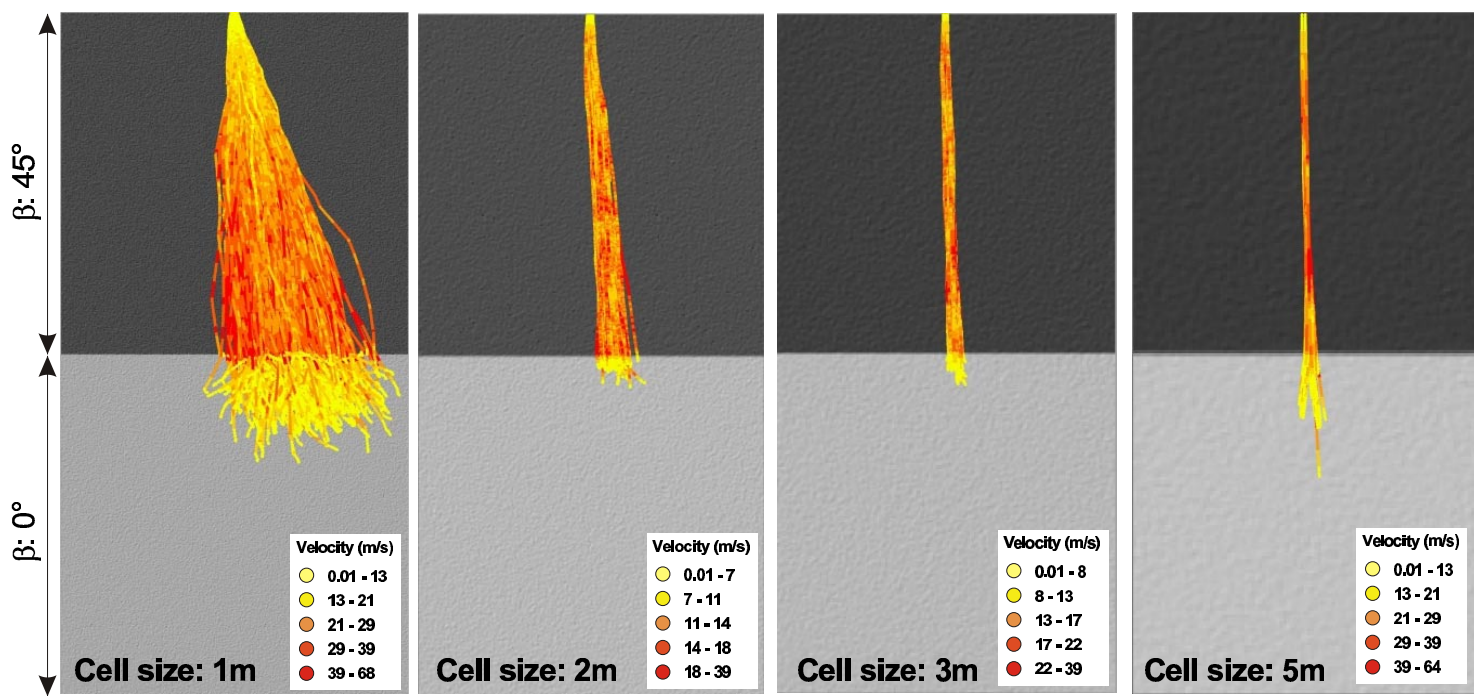

Fig. 5. Plane view of the $3 \mathrm{D}$ trajectories (vector output) computed for synthetic slopes with mean inclination of $45^{\circ}$, maximum roughness $(\sigma=0.2 \mathrm{~m})$ and different cell size of $1,2,3$ and $5 \mathrm{~m}$, respectively. Trajectories are represented by points, classified by translational velocity. Please note that legend color scales are different for each view, because of the very different velocity range obtained for different cell sizes.
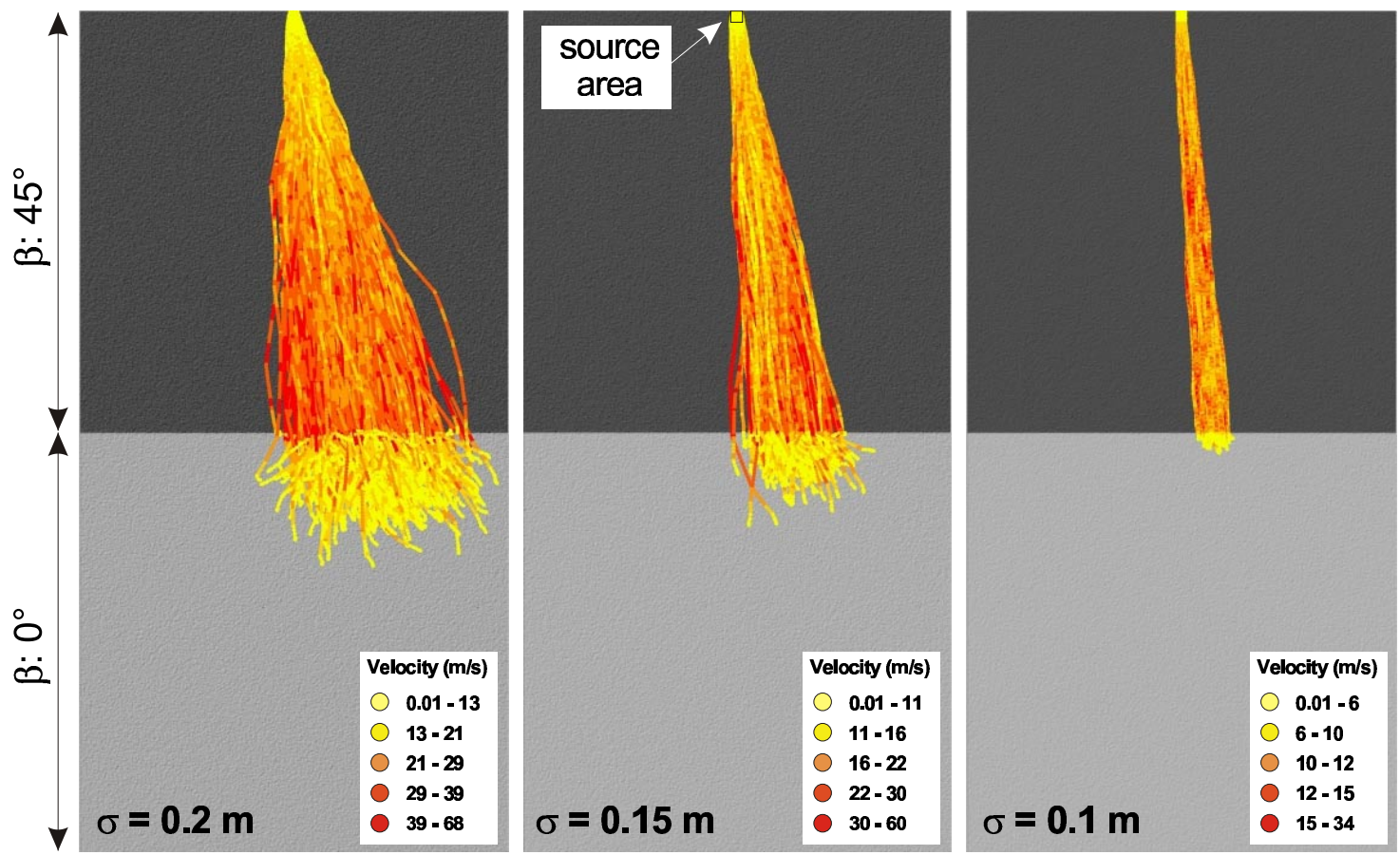

Fig. 6. Plane view of the $3 \mathrm{D}$ trajectories (vector output) computed for synthetic slopes with mean inclination of $45^{\circ}$, $1 \mathrm{~m}$ cell size and different roughness values ( $\sigma=0.2,0.15$ and 0.1 , respectively). Trajectories are represented by points, classified by translational velocity. Please note that legend color scales are different for each view, because of the very different velocity range obtained for different cell sizes.

3D plots shown in Fig. 8 outline the sensitivity of the W/L ratio to the selected controlling variables: cell size, slope roughness $(\sigma)$ and mean slope inclination $(\beta)$. In particular, the highest values of the W/L ratio, ranging from $20 \%$ and $36 \%$, can be observed for very rough slopes and lower values of cell size (Table 1 and Fig. 8). This is in good agreement with the results of high resolution numerical simulation performed by Agliardi and Crosta (2003) for very rough natural slopes, giving W/L values up to the $34 \%$.

The computed values of the W/L ratio show a complex dependence on the mean slope inclination. For a $1 \mathrm{~m}$ cell DEM and maximum roughness (Figs. 8 and 9a) we observed an increase in lateral dispersion with slope inclination up to an inclination of about $45^{\circ}$. Beyond this threshold value the W/L 

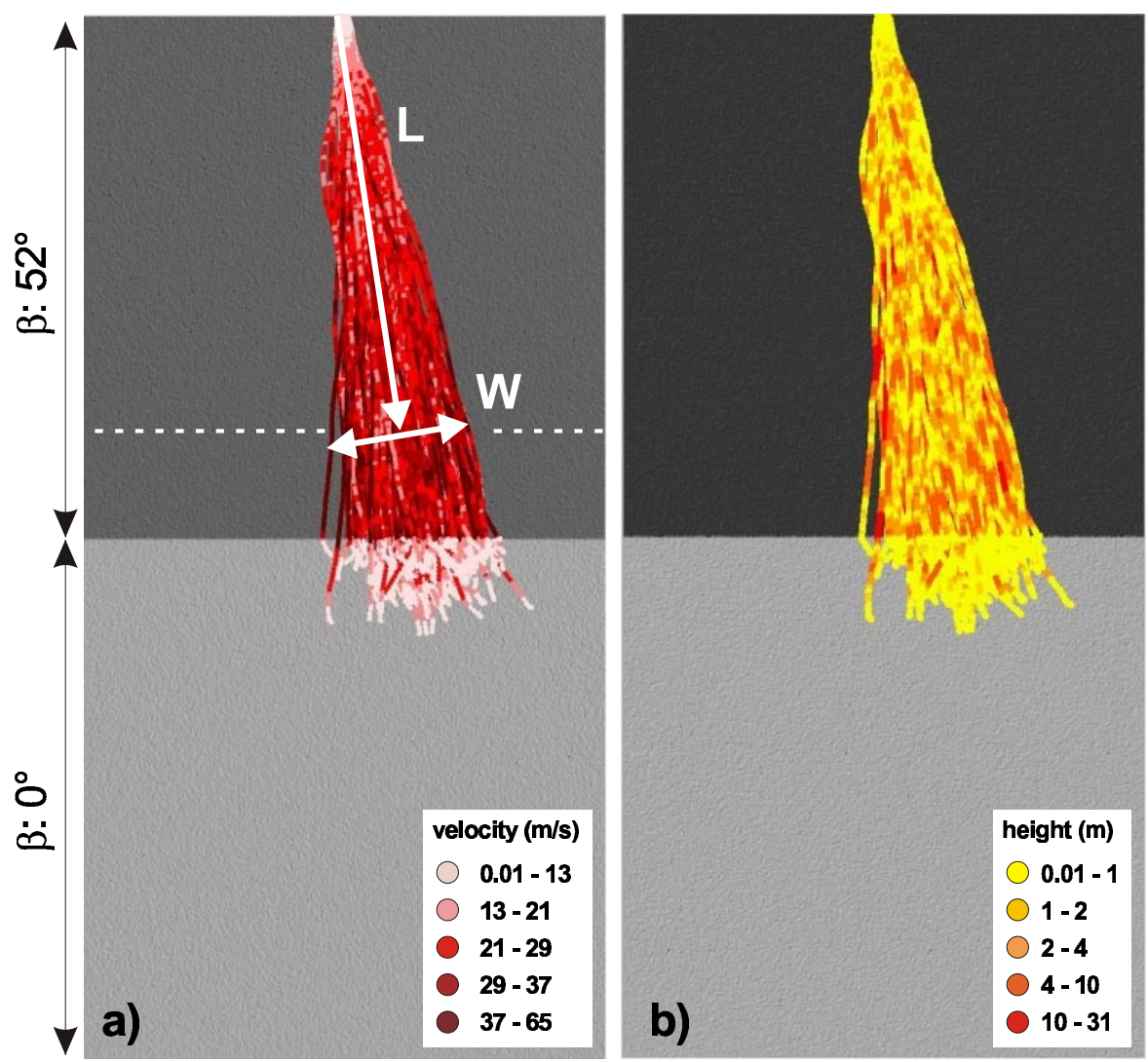

Fig. 7. Measurement scheme used to evaluate the W/L ratio, chosen as the descriptor of lateral dispersion, starting from the computed trajectories. Points are classified by translational velocity (a) and height to the topography (b).

ratio continuously decreases, since the gravitational component becomes dominant in controlling the pattern of rockfall trajectories. This behaviour is different for models with decreasing roughness and/or larger cell size (Figs. 8, 9 and $10)$. For the $2 \mathrm{~m} \mathrm{DEM}$ the W/L ratio decreases for increasing slope inclination and decreasing roughness. Finally, for the $3 \mathrm{~m}$ and $5 \mathrm{~m}$ DEM, the general trend is maintained with low W/L values, especially for average roughness intervals (Figs. 8, 9 and 10).

For fixed values of mean slope inclination (Fig. 10a, b and c), the W/L ratio continuously increases with increasing roughness, at a higher rate for cell size of $1 \mathrm{~m}$ and mean slope inclination of $45^{\circ}$, with an exception for the $5 \mathrm{~m}$ DEM, showing a slightly different trend for smooth, gently dipping slopes. Nevertheless, such a deviation is very small in terms of W/L value, as clearly shown in Fig. 8. Furthermore, the $\mathrm{W} / \mathrm{L}$ ratio shows an exponential decrease with increasing cell size (Figs. 10d, e, f). The maximum rate of decrease can be observed for a mean slope inclination of $45^{\circ}$, which can be regarded as a general threshold separating different trends of behaviour to be considered when dealing with real slopes (Fig. 10). This supports earlier observations by Agliardi and Crosta (2003), suggesting a systematic scale dependence of simulation results on the accuracy of the topographic model, introducing model-specific topographic effects.

\subsection{Topographic control on kinematic variables}

Model results in terms of kinematic variables (local instantaneous velocity and height to the topography) have been analysed through a "moving window" statistical technique, in order to evaluate the sensitivity of rockfall kinematics on different topography-related factors, namely: mean slope inclination, micro-topography (slope roughness) and the spatial resolution of topographic models.

Analyses have been performed by moving a counting circle with a radius of $10 \mathrm{~m}$ along regular grids and computing statistics on the trajectory points falling in the counting circle at each step. This procedure allowed maximum, mean and minimum values of the kinematic variables (i.e. velocity and height) to be obtained over the slope as continuously varying variables (Fig. 11).

For each simulation, the spatial frequency of computed trajectory points (Fig. 11a) has been normalised by the total number, allowing to find a "centreline" for the spatial frequency distribution (Fig. 11b). Then, velocity and height downslope profiles have been extracted by sampling the maximum, mean and minimum grid values along centrelines (Fig. 11c).

The comparative analysis of velocity and height profiles obtained for different values of slope mean inclination $(\beta)$, 

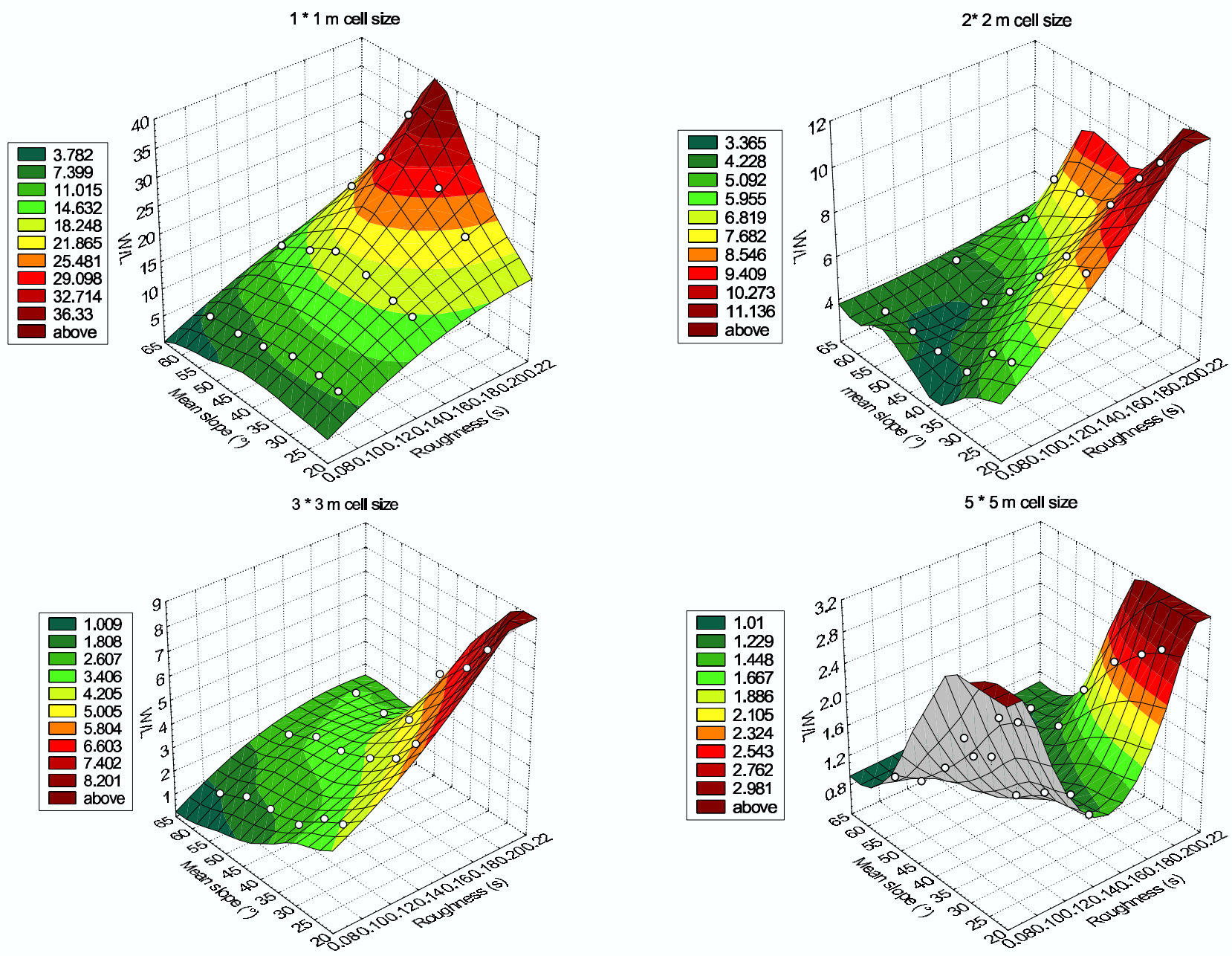

Fig. 8. 3D plots obtained by least square fit of measures W/L values (represented by dots). Plots show the sensitivity of the W/L ratio to slope roughness $(\sigma)$ and mean inclination $(\beta)$, for different values of DEM cell size $(1 \mathrm{~m}, 2 \mathrm{~m}, 3 \mathrm{~m}, 5 \mathrm{~m})$. Please note that plot scale is different for each plot, in order to outline small-scale trends occurring for lower DEM resolution.

slope roughness $(\sigma)$ and DEM spatial resolution (pixel size) allow some important observations to be made. In particular:

- higher values of velocity (Fig. 12) can be observed for increasing mean slope inclination, also resulting in more scattered computed values. This is particularly evident for very rough slopes, where more abundant, higher and slightly longer ballistic parabolas or jumps occur. Nevertheless, for gently dipping slopes, mean and minimum values of velocity are less sensitive to slope roughness than to mean slope inclination;

- bounce height is extremely sensitive to increasing values of slope inclination and roughness (Fig. 13). We observed mean values of bounce height to increase significantly with increasing slope inclination (e.g. less than $1 \mathrm{~m}$ for a $30^{\circ}$ slope up to $9.5 \mathrm{~m}$ for a $52^{\circ}$ slope) and up to 10 times with increasing roughness for the same slope inclination. Maximum values follow a similar trend. This has relevant consequences on the modelling approach and on design procedures for passive countermeasures. For example, a different design approach, based on mean or maximum results, will have important consequences on the requested size (i.e. length and height) and absorbing capability of the countermeasures in order to reduce hazard or to reach a specific residual risk level;

- the spatial resolution of topographic models greatly affects model results. Higher and more scattered values of velocity can be observed for increasing DEM pixel size (decreasing model resolution), while bounce heights decrease with increasing pixel size (Fig. 14). These trends are similar to those reported by Azzoni et al. (1995) and Agliardi and Crosta (2003). Nevertheless, cited authors reported lower scattering of computed velocity and bounce height for decreasing resolution of the topographic model (2D slope profile or DEM), while in this research an opposite trend has been outlined for velocity values. This difference could be possibly accounted 

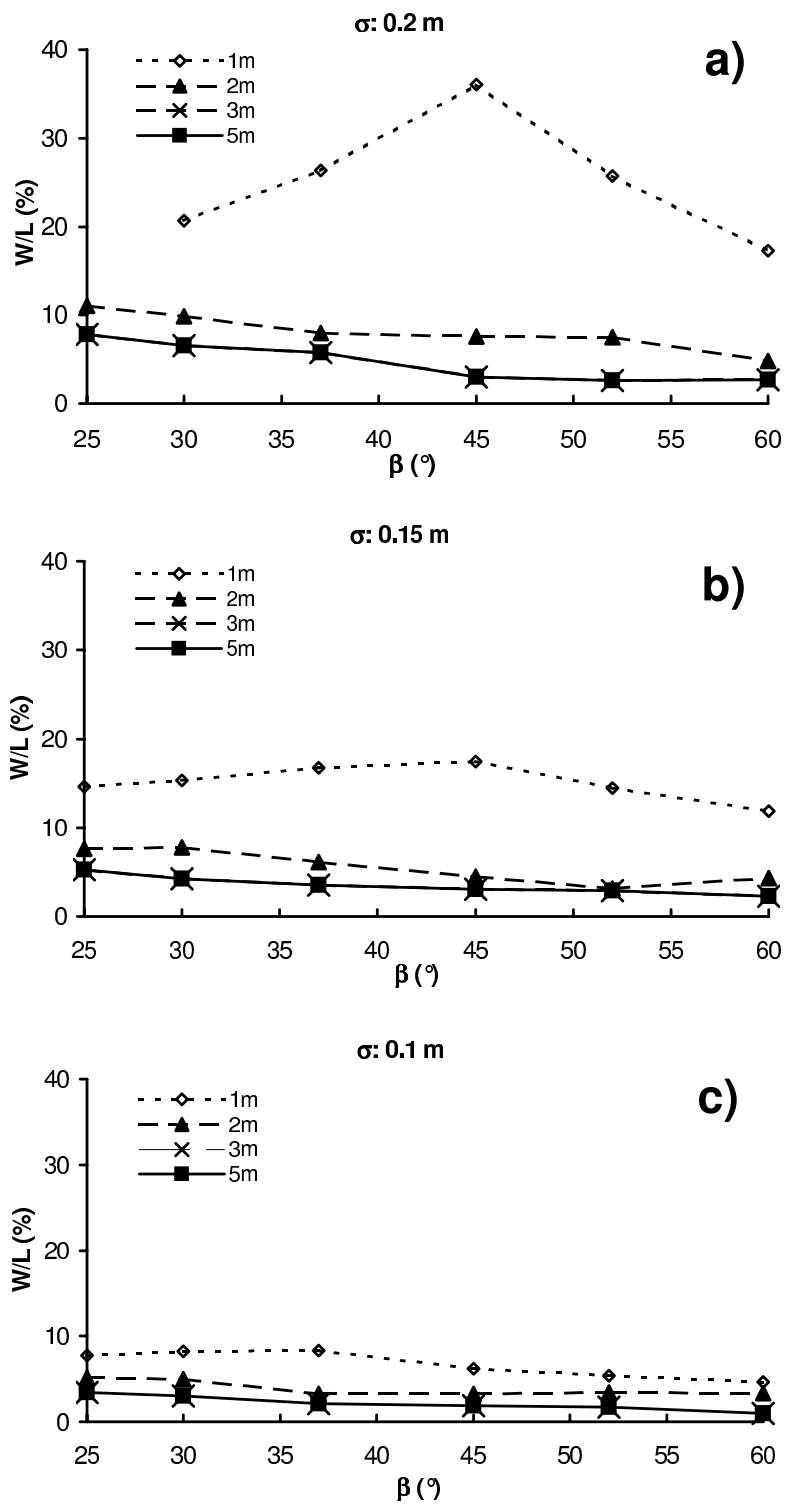

Fig. 9. 2D plots showing the sensitivity of the W/L ratio to DEM spatial resolution (pixel size) and mean slope inclination $(\beta)$, for different values of slope roughness $(\sigma)$. Plots can be considered as cross sections of the 3D plots of Fig. 8 .

for by invoking DEM-related issues. In fact, the synthetic biplanar slopes used for parametric modelling are characterised by significant roughness at the original $1 \mathrm{~m}$ resolution. Such a degree of roughness, only partially reduced by the resampling process adopted to up-scale the topographic information, introduce a high variability of local topography even at lower DEM resolutions.

The solution of rockfall problems in practice always requires evaluating the downslope distribution of kinematic variables, in order to optimise countermeasures design (Richards, 1986; Spang, 1987; Stevens, 1998) and hazard assessment (Crosta and Agliardi, 2003). From this perspective, paramet- ric modelling allows to establish some reference point for engineering applications.

In particular, plots in Fig. 12 clearly put in evidence the onset of "steady-state" kinematic conditions for smooth and gently dipping slopes. This means that almost constant values for the rockfall velocity are reached faster in case of smoother slopes than for rougher ones. Furthermore, for a fixed value of slope mean inclination steady state is reached more easily with minimum slope roughness $(0.1 \mathrm{~m})$ and small DEM cell size (high resolution topographic model).

The possibility for block velocities to reach a steady state appear to be linked to the most probable type of motion occurring on specific slopes. According to experimental observations (Ritchie, 1963; Broili, 1973), rolling and short bounces dominate on gently dipping slopes, while higher mean inclinations are associated to bouncing motions. Nevertheless, the analysis of the computed velocity profiles show the major influence of slope roughness on the onset of different motions (Fig. 12). In particular, some typical situations can be recognised:

- for gently dipping slopes (e.g. $\beta=37^{\circ}$ in Fig. 12) slightly accelerating rolling motions alternate with regularly spaced short bounces. Under these conditions kinetic energy is continuously accumulated and lost, allowing for a sudden onset of "steady state" conditions for any roughness condition, especially for mean computed velocity values;

- for steeper smooth slopes (e.g. $\beta=52^{\circ}$ and $\sigma=0.1 \mathrm{~m}$ in Fig. 12), short bounces dominate, allowing for mean velocity to reach steady-state condition, even though maximum values are more scattered and irregularly distributed;

- for steeper rough slopes (e.g. $\beta=52^{\circ}$ and $\sigma=0.2 \mathrm{~m}$ in Fig. 12), dominant motions consist of continuously accelerating rolling or irregular, high and long ballistic jumps, with increasing and highly scattered velocity values, which hamper the reach of steady conditions.

\section{Discussion and conclusions}

Despite apparently simple and seldom spectacular, rockfalls are fairly complicated phenomena, since they involve complex physics and major stochastic components. Thus, performing reliable and consistent modelling in engineering practice is sometimes very difficult. In fact, rockfall trajectories are strongly influenced both by mechanical and geometrical conditions, and motion on a real three-dimensional slope is much more complex or irregular than in the twodimensional world of the most successful rockfall models available for engineers. Thus, the results of numerical modelling of rockfalls are very sensitive to both the mechanical parameters and the morphological description, largely affecting the reliability of engineering evaluation of rockfalls, especially when geometrically complex slopes are involved. 

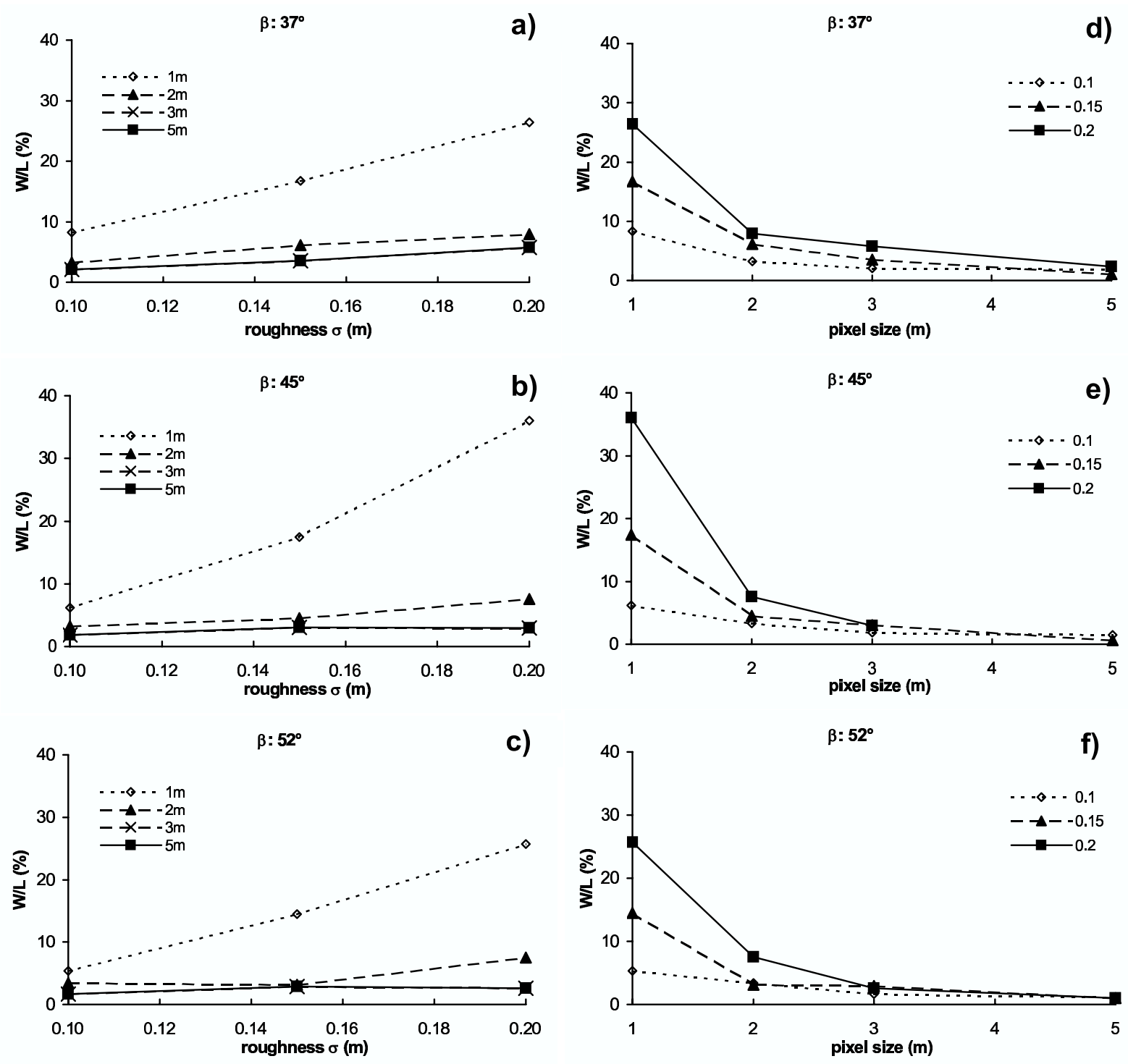

Fig. 10. 2D plots showing the sensitivity of the W/L ratio to slope roughness $(\sigma)$ and DEM spatial resolution (pixel size), for different values of mean slope inclination $(\beta)$. Plots can be considered as cross sections of the 3D plots of Fig. 8 .

In this research, the sensitivity of lateral dispersion of rockfall trajectories has been systematically evaluated as a function of macro-topographic, micro-topographic and model specific features. The analyses proved such a sensitivity to be very significant in affecting the practical zonation of rockfall runout areas and the capability of reliably assessing rockfall hazard. This supports the need for design and hazard assessment procedures to be based on the use of carefully calibrated 3D modelling. Furthermore, the major influence of 3D topographic features on rockfall dynamics, often under-estimated in the past, has been pointed out.

Both the lateral dispersion and the kinematic variables (velocity and the bounce height) of simulated rockfalls strongly depend on slope mean inclination and roughness. Also, the accuracy of the topographic description (DEM resolution in this study) and other model-specific parameters affect the value and the spatial distribution of the kinematic quantities, with evident consequences on passive countermeasure design procedures and on hazard zonation.

Modelling results allow to outline some typical conditions, useful to suggest some practical rules to engineers dealing with significantly three-dimensional slopes. In particular:

- for smooth and gently dipping slopes one can expect a moderate amount of lateral dispersion and kinematic conditions close to steady state. A combination of low and short jumps and a constant velocity seems to be typical of steady state conditions along slopes of medium to low inclination. This behaviour could be more evident on real natural slopes when the moving block becomes progressively more rounded (i.e. decreasing relative roughness, friction coefficient and out of centre forces); 

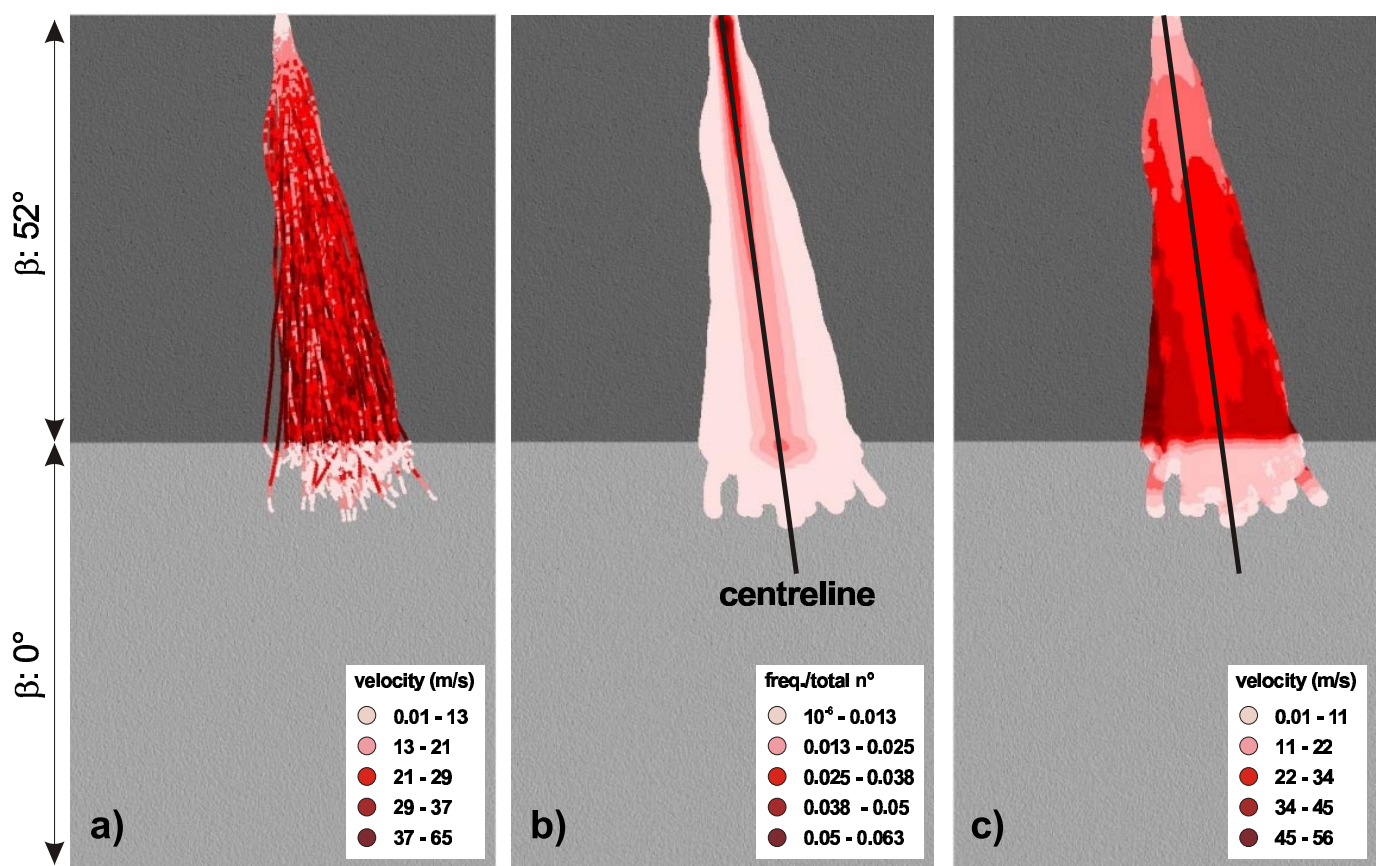

Fig. 11. Moving window statistical analysis of simulation results (a), performed by moving a counting circle with $10 \mathrm{~m}$ radius over a regular grid. The spatial frequency of computed trajectory points has been normalised by the total, allowing to find the centreline of the spatial distribution of trajectories (b). Centrelines have then been used as profile traces to sample velocity and height values from the grids computed by moving window statistics (c, mean velocity).
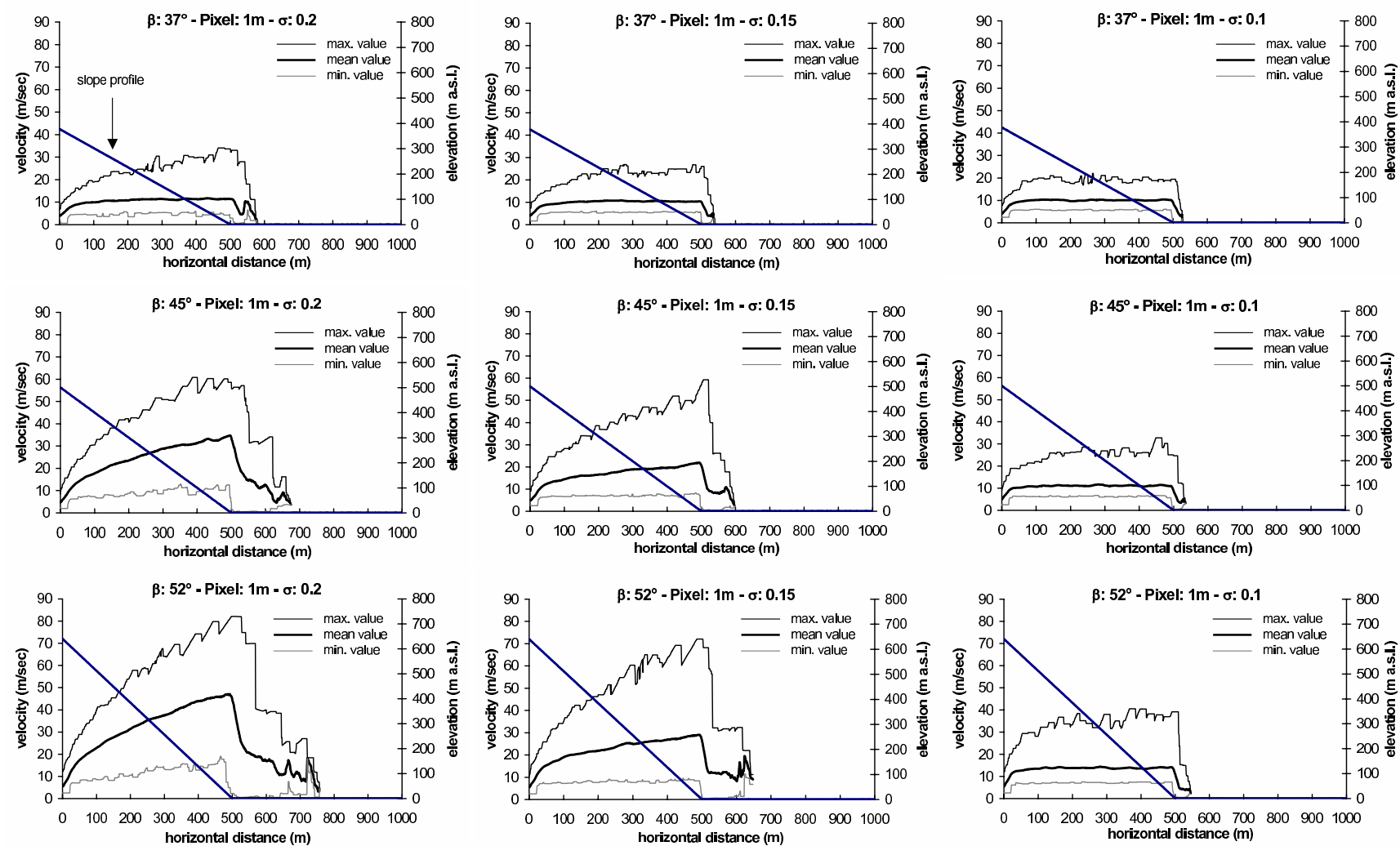

Fig. 12. Velocity profiles sampled from the results of moving window statistics (see Fig. 11), showing the sensitivity of the computed velocities to slope mean inclination $(\beta)$ and roughness $(\sigma)$, for a fixed DEM resolution $(1 \mathrm{~m})$. 

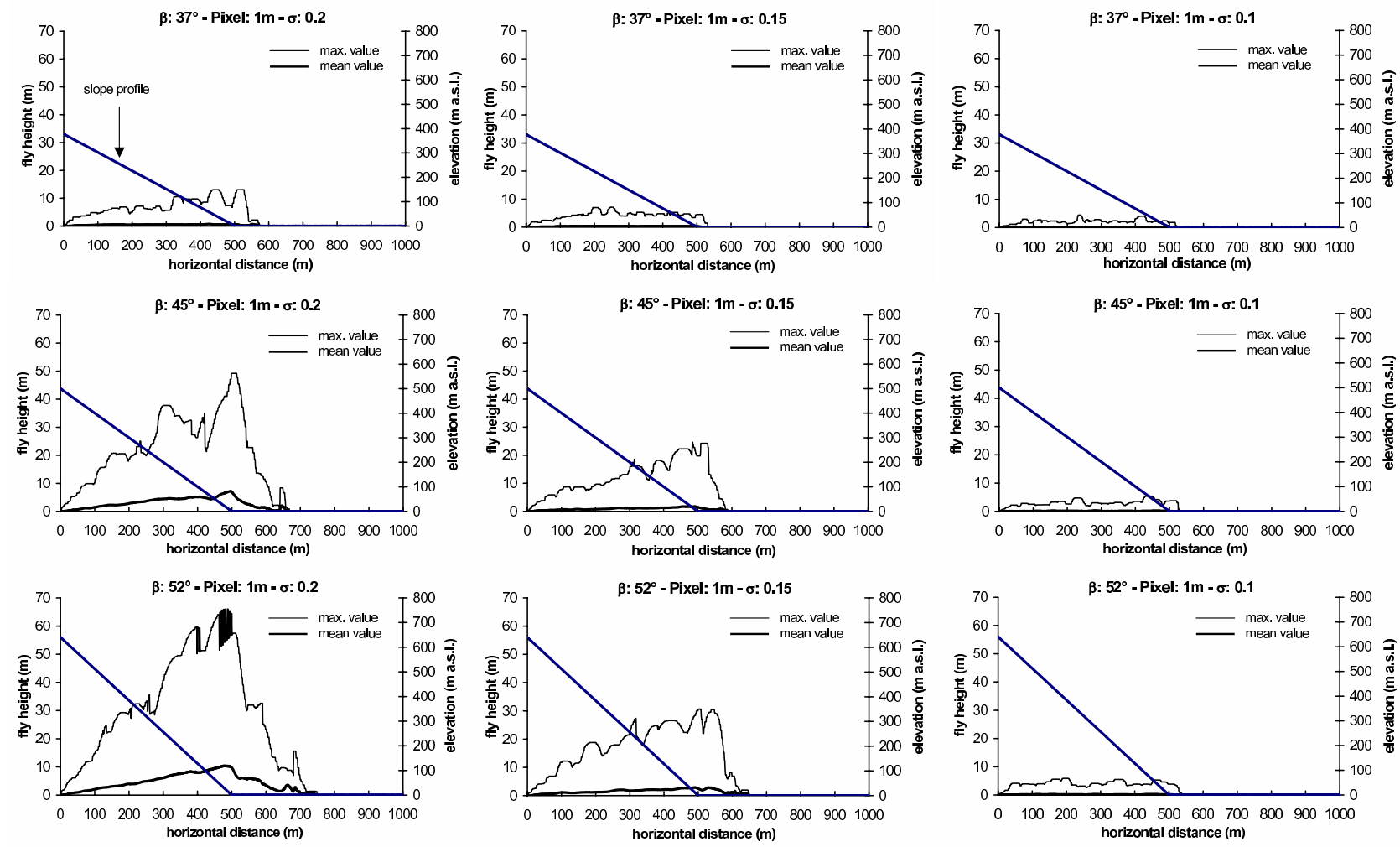

Fig. 13. Fly height profiles sampled from the results of moving window statistics (see Fig.11), showing the sensitivity of the computed fly height to slope mean inclination $(\beta)$ and roughness $(\sigma)$, for a fixed DEM resolution $(1 \mathrm{~m})$.

- for very rough slopes, lateral dispersion is expected to increase with increasing mean slope inclination up to the threshold value of $45^{\circ}$ (e.g. blocky talus slopes) for which W/L ratios up to $30-35 \%$ could be reached, with obvious consequence on countermeasure design. Moreover, under these conditions steady-state motion is hardly reached, and continuously accelerating rolling and bouncing motions should be expected;

- lateral dispersion should be expected to be low (less than $15 \%$ ) for short and very steep slopes (e.g. rocky slopes). In this case, the use of 2D models can be acceptable and more attention should be paid to the careful evaluation of the kinematic variables, since unsteady and highly scattered values of velocity and bounce height should be expected.

The practical rules suggested above could be used to preliminary assess the expected rockfall behaviour, in order to plan data collection strategies and to choose the most suitable modelling tools and design approaches (e.g. the use of average of maximum values for kinetic energy, etc.). Nevertheless, practical rules have to be employed with caution, since they are obtained by numerical modelling under restricted conditions. Thus, their verification through field observations, experimental data and robust, carefully calibrated numerical modelling is always needed.
Furthermore, when performing numerical modelling in engineering practice, the quality of elevation data available for the generation of the topographic model (contour lines, raster DEMs, vector triangulate networks, etc.) strongly affects the reliability of simulation results. This could have some important effects on the modelling strategy and in extreme cases could favour the use of 2D simulation tools with respect to 3D ones. For example, 2D modelling and a subjective choice of the most probable rockfall path can be considered reasonable when a low detail topographic description is available, and/or in presence of low micro-topographic relief (smooth slopes), and absence of channels and concavities, on steep slopes $\left(>40^{\circ}\right)$. In other cases, all the micro- and macro-topographical features will interact controlling velocity, height and lateral dispersion of the trajectories. In particular, the design choice of the maximum height and energy absorption capability of barriers, as well as their length (transversal to the rockfall path), can be strongly influenced. In fact, neglecting the lateral dispersion of the trajectories will induce an underestimation of the barrier length needed to ensure protection to a specific design area. Open channels and feeble longitudinal concavities could also suggest a containing effect on rockfall trajectories resulting in a reduced extension of hazardous areas. This assumption could be verified through an accurate 3D modelling approach including both 3D morphologies and dispersion effects. 

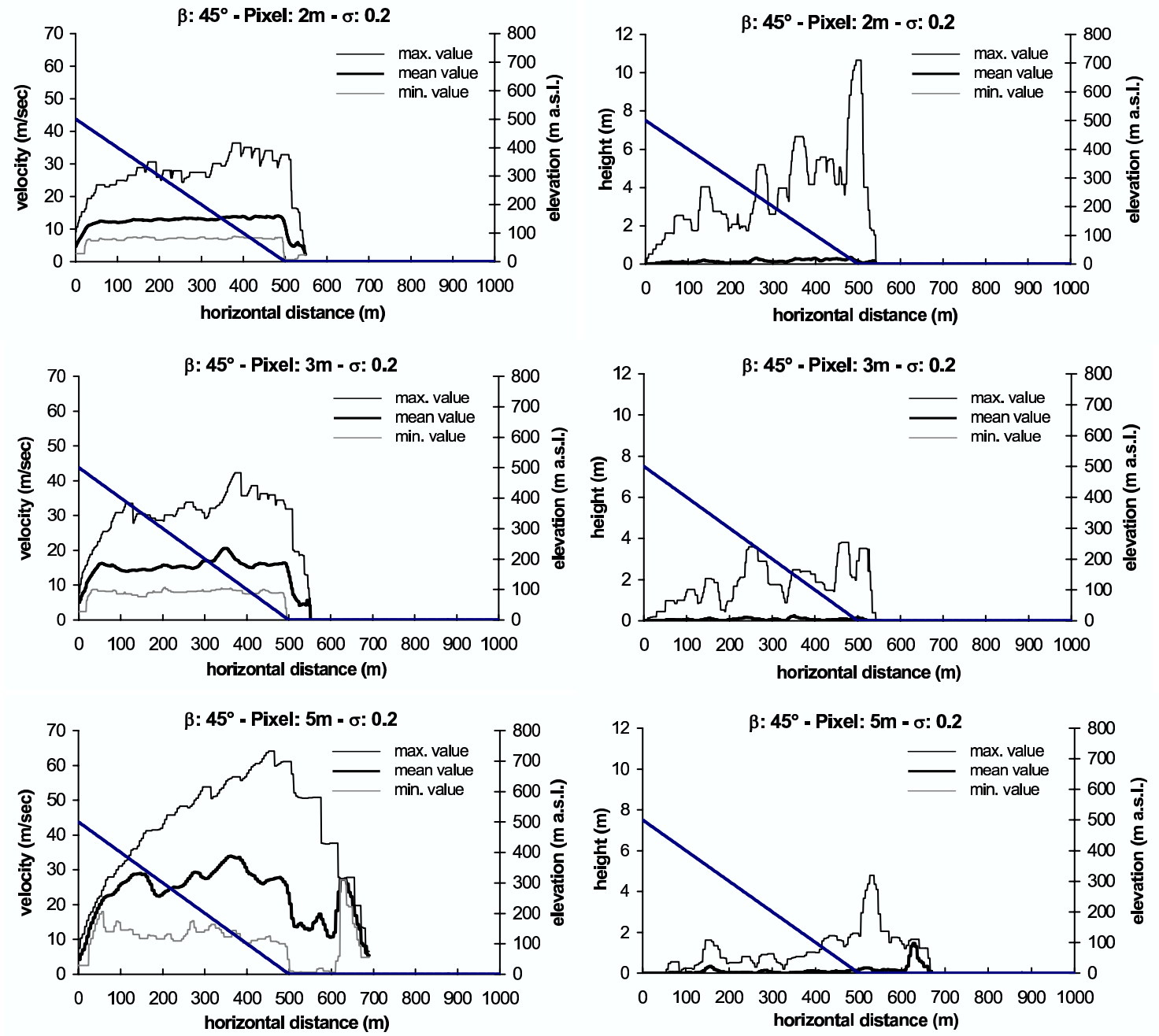

Fig. 14. Velocity and height profiles sampled from the results of moving window statistics (see Fig. 11), showing the sensitivity of the rockfall kinematic quantities (velocity and height) to the spatial resolution of the topographic model, for fixed values of slope mean inclination $\left(\beta=45^{\circ}\right)$ and roughness $(\sigma=0.2 \mathrm{~m})$.

The reliability of modelling results is also strongly influenced by the value of model specific simulation parameters, which must be evaluated through accurate sensitivity analyses before any reliable modelling could be performed. For example, Fig. 15 shows the influence of the threshold value controlling the transition from bouncing to rolling simulation algorithm in the simulation program. The threshold value, expressed in terms of bounce length (Guzzetti et al., 2002; Agliardi and Crosta, 2003), clearly affects the mode of motion along the slope profile and, as consequences, the distribution of the kinematic variables and the possibility for blocks to reach steady-state motion conditions. Figures 14 and 15 show that a superficial use of modelling tools could easily cause misinterpretation of the processes and of the results with relevant consequences on hazard zonation and design of passive countermeasures.

Finally, it can be stressed that the values usually assumed for the coefficients of restitution and the friction coefficient contain implicit information about local micro-topographic conditions (slope roughness, vegetation, etc.) and/or block geometry (angularity, roundness, etc.). As a consequence, different values could be chosen to perform numerical simulations and to calibrate models when topographic descriptions of different detail and scale are available. This also suggests that a detailed description of the slope surface should be given when values of the coefficients are obtained from in situ tests. For example, a talus slope could be covered with small or large blocks with respect to the falling block size and this will control the final restitution and friction coefficients. The same problem can arise when different types of description (kinematic or dynamic) of motion are adopted. In this last case a careful choice of the coefficients must be done.

We are presently running more simulations to consider the effects on the numerical results of different restitution and friction coefficients as well as those due to the introduction of the dynamic components of motion. This will help in the evaluation of the sensitivity of the numerical approach and of 

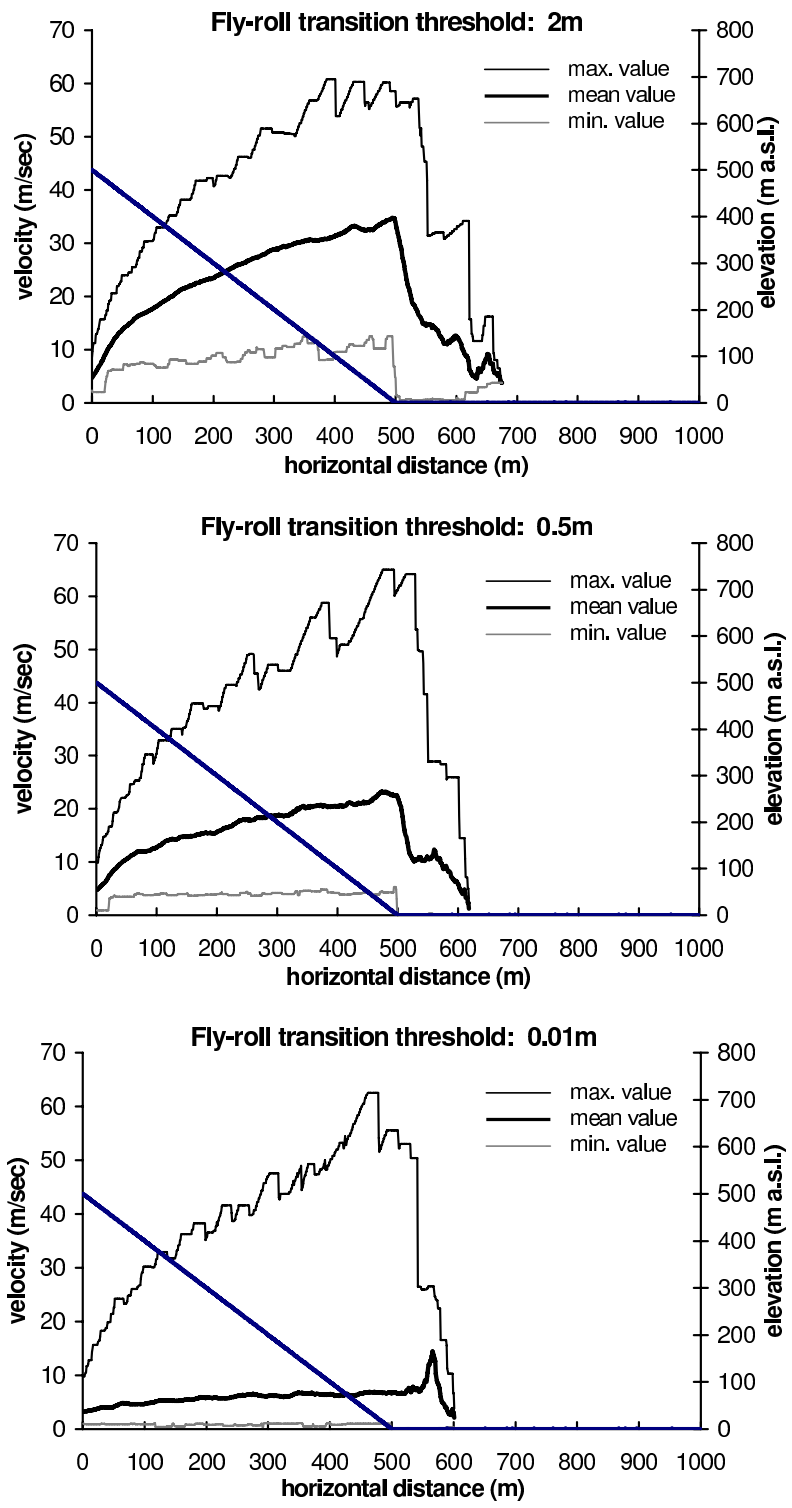

Fig. 15. Velocity profiles sampled from the results of moving window statistics (see Fig. 11) for fixed values of DEM resolution ( $1 \mathrm{~m})$, slope mean inclination $\left(\beta=45^{\circ}\right)$ and roughness $(\sigma=0.2 \mathrm{~m})$, showing the sensitivity of results to a code-specific parameter, i.e. the threshold value controlling transition from bouncing to rolling in the simulation algorithm.

its results to the adopted values of the physical-mechanical parameters and to the level of detail of morphological slope description.

Acknowledgements. The authors are grateful to S. Imposimato for her important contribution to the development of the simulation program and to M. Jaboyedoff for sharing stimulating discussions on rockfall-related topics. The paper benefited from the suggestions of S. Silvano and of an anonymous referee.

Edited by: L. Marchi

Reviewed by: S. Silvano and another referee

\section{References}

Acosta, E., Agliardi, F., Crosta, G. B., and Rìos Aragùes, S.: Regional rockfall hazard assessment in the Benasque Valley (Central Pyrenees) using a 3D numerical approach, in: Mediterranean Storms, edited by: Jansà, A. and Romero, R., Proc. 4th EGS Plinius Conference, Mallorca, Spain, 2003.

Agliardi, F.: Frane di crollo e caduta massi: modellazione numerica $3 \mathrm{D}$ e valutazione della pericolosità. Tesi di dottorato in Scienze della Terra (XV ciclo), Università degli Studi di Milano, 228 pp, 2003 (in Italian), 2003.

Agliardi, F. and Crosta, G. B.: 3D numerical modelling of rockfalls in the Lecco urban area (Lombardia Region, Italy), in: Proc. EUROCK 2002, I.S.R.M. International Symposium on Rock Engineering for Mountainous Regions and Workshops on Volcanic Rocks, edited by: Dinis de Gama, C. and Ribeiro Sousa L., Madeira, Portugal, 79-86, 2002.

Agliardi, F. and Crosta, G. B.: High resolution three-dimensional numerical modelling of rock falls, Int. J. Rock Mech. Min. Sci., 40(4), 455-471, 2003.

Azzoni, A., La Barbera, G., and Zaninetti, A.: Analysis and prediction of rockfalls using a mathematical model, Int. J. Rock Mech Min. Sci. \& Geomech. Abstr., 32 (7), 709-724, 1995.

Bozzolo, D. and Pamini, R.: Simulation of rockfalls down a valley site, Acta Mechanica, 63, 113-130, 1986.

Bozzolo, D., Pamini, R., and Hutter, K.: Rockfall analysis - a mathematical model and its test with field data, Proc. 5th Int. Symposium on Landslides, Lausanne, Switzerland, 1, 555-563, 1988.

Broili, L.: In situ tests for the study of rockfall, Geologia Applicata e Idrogeologia, 8 (1), 105-111, 1973.

Bunce, C. M., Cruden, D. M., and Morgenstern, N. R.: Assessment of the hazard from rockfall on a highway, Can. Geotech. J., 34, 344-356, 1997.

Cancelli, A. and Crosta, G. B.: Hazard and risk assessment in rockfall prone areas, in: Risk Reliability in Ground Engineering, edited by: Skipp, B. O., Inst. Civ. Eng., Thomas Telford, 177190, 1993.

Crosta, G. B. and Agliardi, F.: A methodology for physically-based rockfall hazard assessment, Natural Hazards and Earth System Sciences, 3, 407-422, 2003,

SRef-ID: 1684-9981/nhess/2003-3-407.

Crosta, G. B. and Locatelli, C.: Approccio alla valutazione del rischio da frane per crollo, Proc. Studi geografici e geologici in onore di Severino Belloni, Glauco Brigatti Publisher, Genova, 259-286 (in Italian), 1999.

Crosta, G. B., Agliardi, F., Frattini, P., and Imposimato, S.: A three dimensional hybrid numerical model for rockfall simulation, Geophys. Res. Abstr., Vol. 6, 04502, 2004.

Evans, S. G. and Hungr, O.: The assessment of rockfall hazard at the base of talus slopes, Can. Geotech. J., 30, 620-636, 1993.

Guzzetti, F., Crosta, G. B., Detti, R., and Agliardi, F.: STONE: a computer program for the three-dimensional simulation of rockfalls, Computers and Geosciences, 28 (9), 1081-1095, 2002.

Heim, A.: Bergsturz und Menschenleben. Fretz and Wasmuth Verlag, Zurich, 218 pp., 1932.

Hungr, O. and Evans, S. G.: Engineering evaluation of fragmental rockfall hazards, Proceedings 5th International Symposium on Landslides, Lausanne, 1, 685-690, 1988.

Jaboyedoff, M. and Labiouse, V.: Preliminary assessment of rockfall hazard based on GIS data. Proceedings ISRM 2003 - Technology roadmap for rock mechanics, South African Institute of Mining and Metallurgy, 575-578, 2003. 
Jones, C. L., Higgins, J. D., and Andrew, R. D: Colorado Rockfall Simulation Program Version 4.0, Colorado Department of Transportation, Colorado Geological Survey, 127 pp., 2000.

Kobayashi, Y., Harp, E. L., and Kagawa, T.: Simulation of rockfalls triggered by earthquakes, Rock Mech. Rock Eng., 23, 1-20, 1990.

Matsuoka, N. and Sakai, H.: Rockfall activity from an alpine cliff during thawing periods, Geomorphology, 28, 309-328, 1999.

Pfeiffer, T. and Bowen, T.: Computer simulation of rockfalls, Bull. Ass. Eng. Geol., 26 (1), 135-146, 1989.

Ritchie, A. M.: Evaluation of rockfall and its control, Highway Research Board, Highway Res. Rec., 17, 13-28, 1963.

Rochet, L.: Application des modèles numériques de propagation à l'étude des éboulements rocheux, Bulletin des Laboratoire des Ponts et Chaussèes, 150/151, 84-95 (in French), 1987.

Richards, L. R.: Rockfall protection: a review of current analytical and design methods. In Secondo Ciclo di Conferenze di Meccanica e Ingegneria delle Rocce, MIR, Chap. 11, Torino, 1-13, 1986.
Spang, R. M.: Protection against rockfall - stepchild in the design of rock slopes, Proc. 6th Int. Cong. on Rock Mechanics, Montreal, Canada, 551-557, 1987.

Stevens, W.: RocFall: a tool for probabilistic analysis, design of remedial measures and prediction of rockfalls, M.A.Sc. Thesis, Department of Civil Engineering, University of Toronto, Ontario, Canada, 105 pp, 1998.

Varnes, D. J.: Slope movements: types and processes, in: Landslide analysis and control, Transportation Research Board, Special Report 176, edited by: Schuster, R. L. and Krizek, R. J., Washington D.C., 11-33, 1978.

Wieczorek, F. G., Morrissey, M. M, Iovine, G., and Godt, J.: Rockfall Potential in the Yosemite Valley, California, U.S. Geological Survey Open-File Report 99-578, 10 pp., 1999.

Wu, S. S.: Rockfall evaluation by computer simulation: Transportation Research Record, Transportation Research Board, Washington, DC, 1031, 1-5, 1985. 